\title{
Determinants of World Demand for U.S. Corn Seeds: The Role of Trade Costs
}

\author{
Revised March 31, 2010
}

\begin{abstract}
The United States is a large net exporter of corn seeds. Seed trade, including that of corn, has been expanding, but its determinants are not well understood. This paper econometrically investigates the determinants of world demand for U.S. corn seeds with a detailed analysis of trade costs impeding export flows to various markets, including costs associated with distance, tariffs, and sanitary and phytosanitary (SPS) regulations. The analysis relies on an explicit specification of derived demand for seed by foreign corn producers, estimated based on data from 48 countries for the years 1989 to 2004. An SPS count variable is incorporated as a shifter in the unit cost of seeds faced by foreign users. A sample selection framework is used to account for the large presence of zero trade flows. All trade costs matter and have had a negative impact on U.S. corn seed exports. Tariffs matter most, followed by distance and SPS measures.
\end{abstract}

Keywords: Corn, distance, phytosanitary, seeds, SPS, tariff, technical barriers, trade cost.

JEL code: Q17, Q 18, F13, F14 


\section{Introduction}

The U.S. commercial seed market is the world's largest, with an estimated annual value exceeding $\$ 6$ billion per year in the late 1990s, followed by those of China and Japan. Over the past decade, the U.S. seed market has been growing in quantity and value, particularly for major field crops such as corn, soybeans, cotton, and wheat, which constitute two-thirds of the commercial seed market in the United States (Fernandez-Cornejo and Caswell, 2006). Seed trade has been an integral part of this market expansion. The United States is a net and large exporter of corn seed for planting. The U.S. corn seed export value grew from approximately US\$68.5 million in 1989 to $\$ 174$ million in 2004. Italy, Mexico, Canada, France, and Spain are the largest importers of U.S. corn seed. Together, these countries accounted for approximately 60 percent of total U.S. corn seed exports in $2004 .{ }^{1}$ However, seed trade is arguably underdeveloped with much potential to expand, especially in developing countries (McGee, 1998). Only 10 percent of total U.S. commercial seed goes to developing countries such as India and China. These two countries represent large potential seed markets, along with Brazil and Argentina (Fernandez-Cornejo, 2004).

The use of standards and technical regulations as instruments of commercial policy in world agri-food trade has been rising, as tariff and quota barriers continue to decline and as consumers demand safer agri-food products (Beghin, 2008; Henson and Wilson, 2005). Among non-tariff measures, sanitary and phytosanitary (SPS) regulations and technical barriers to trade (TBTs) are of increasing importance as impediments to, and sometimes facilitators of, agri-food trade (Disdier, Fontagné, and Mimouni, 2008; and Moenius, 2006).

Despite the substantial body of work analyzing the impact of standards and technical

\footnotetext{
${ }^{1}$ On a regional basis, North America (36 percent), Western Europe (32 percent), Asia (11 percent), other European countries (6 percent), and South America (4 percent) accounted for 89 percent of the total quantity of U.S. exports in 2004.
} 
regulations on agricultural and food trade, little is known about seed trade determinants. Seed trade policies have not attracted much attention from economists, although seed scientists have raised concerns about SPS policies (Rohrbach, Minde, and Howard, 2003; and McGee, 1998). The U.S. seed industry faces significant problems satisfying SPS regulations because of increasing concerns about seed safety, stricter SPS requirements in trade, competitiveness in export markets, and, occasionally, protectionism.

There is a large literature on the analysis of TBTs and SPS measures, including Anderson, McRae, and Wilson (2001); Beghin and Bureau (2001); Deardorff and Stern (1998); and Maskus and Wilson (2001). Henson and Wilson (2005) provide a comprehensive discussion of these and other earlier contributions. Cipollina and Salvatici (2007) review more recent developments on this topic. Recent analyses include Calvin, Krissoff, and Foster (2008); Peterson and Orden (2008); Yue, Beghin, and Jensen (2006); and Yue and Beghin (2009). Conspicuously absent in this SPS literature are explicit analyses of seed trade determinants and the impact of associated SPS regulations. This void is surprising because seeds are well-known vectors of invasive pests and species propagation. Accordingly, SPS measures have been extensively used in world seed trade in order to mitigate the introduction of exotic species, pests, and diseases, and to limit risks to human and animal health. Examples include quarantines, inspections, tests, certificates, fumigation, and outright bans.

This paper fills this gap and addresses the following questions: What does actually determine seed trade among a list of presumed relevant factors (relative seed price, corn output, tariff, transportation cost, and SPS policies), and what is their relative importance? These are pertinent research questions, which lead to a formal elucidation of seed trade and its policy determinants. To estimate the factors determining world demand for U.S. seed 
corn exports, we develop a parsimonious seed export demand model and use it for an econometric investigation of world demand for U.S. corn seeds. The empirical analysis relies on a newly constructed data set covering major corn and silage producing countries and their trade policies (tariffs and SPS measures), which are faced by U.S. seed exporters. The frequency measure of SPS policies is based on the EXCERPT (Export Certification Project Demonstration) regulation database collected for the U.S. Department of Agriculture (USDA), Animal and Plant Health Inspection Service (APHIS), by Purdue University.

Our investigation relies on a sectoral gravity-equation-type model. An original feature of our setup is that the model is grounded in intermediate demand rather than final demand as are most other gravity models. Many agricultural products are indeed intermediate inputs used in other industries, and thus our specification is likely to be of interest for other agricultural trade applications. The applied trade literature has neglected this simple but important point on the differentiation of intermediate and final demands (see also Ghazalian et al. (2007) for a related intermediate demand approach). We find that trade costs are important determinants of seed export demand: tariffs, SPS regulations, and distance negatively affect U.S. corn seed export demand.

\section{A Gravity Equation for Imported Seed Demand}

As in many gravity models, we use the simple constant elasticity of substitution (CES) structure to incorporate the intermediate demand for corn seed in corn production and eventually to calculate the tariff equivalent estimate of SPS regulations. The significant departure is that the CES applies to production rather than to final consumer preferences. Taking a dual approach to the specification of this technology, the cost function for corn production derived from a CES production function can be written as follows: 


$$
C_{j}=Q_{j}\left(\sum_{i=1}^{n} \theta_{i} W_{i j}^{1-\sigma}+\sum_{k=1}^{m} \mu_{j k} R_{j k}^{1-\sigma}\right)^{\frac{1}{1-\sigma}}
$$

where $Q_{j}$ is corn production for country $j ; W_{i j}$ is the price paid by corn producers of country $j$ for their seed corn sourced in country $i ; R_{j k}$ is the price of the kth non-seed input used in country $j ; \sigma$ is a parameter that determines the degree of substitutability of the inputs; and $\theta_{i}$ and $\mu_{j k}$ are technology productivity parameters associated with the various inputs used. Note that we assume that the productivity parameters of the seed input are the same in all countries, although seeds sourced in different countries can have different productivity. With that we try to capture, somewhat roughly, the fact that origindifferentiated seeds may differ in quality and may be imperfect substitutes. On the other hand, the $\mu_{j k}$ parameters associated with non-seed inputs are allowed to differ across countries, and thus we do allow for some heterogeneity in the technology for final corn production.

The conditional factor demands for corn seeds, by Shephard's lemma, are

$$
X_{i j}=\frac{\theta_{i}}{W_{i j}^{\sigma}} Q_{j}\left(\sum_{i=1}^{n} \theta_{i} W_{i j}^{1-\sigma}+\sum_{k=1}^{m} \mu_{j k} R_{j k}^{1-\sigma}\right)^{\frac{\sigma}{1-\sigma}} .
$$

Seed input prices at destination $j$ can be written as

$$
W_{i j}=W_{i} T_{i j}
$$

where $W_{i}$ is the export unit price (FOB) of seed corn sourced in country $i$ and $T_{i j} \geq 1$ is the trade cost factor (also known as trade resistance) that reflects the impacts of tariffs, distance, and SPS regulations affecting the price of seed corn from country $i$ and landed in country $j$. By using equation (3), the seed import demand in each country can be expressed as

$$
X_{i j}=\theta_{i} Q_{j} c_{j}^{\sigma} W_{i}^{-\sigma} T_{i j}^{-\sigma},
$$


where $c_{j}$ is the unit cost function for corn production defined as

$$
c_{j}=\left(\sum_{i=1}^{n} \theta_{i}\left(W_{i} T_{i j}\right)^{1-\sigma}+\sum_{k=1}^{m} \mu_{j k} R_{j k}^{1-\sigma}\right)^{\frac{1}{1-\sigma}} .
$$

Demand equations for non-seed inputs could similarly be derived from (1). But in our application we will not have data on them, and so we work with a specialized formulation that allows us to sidestep the modeling of their explicit impacts. Specifically, to proceed we will assume a competitive structure in final corn production, which justifies the constant return to scale (CRTS) assumption implicit in our CES specification. In a competitive equilibrium, therefore, the unit production cost $c_{j}$ will equal the expected output price, i.e., the expected corn price in country $j$. Furthermore, we do not have data on seed imports from all destinations, but we do have detailed data on export of U.S. corn seeds. So, in what follows we focus on trade in corn seed coming from a single source (the United States).

\subsection{A model for U.S. corn seed exports}

Because we consider seed sourced in the Unites States only, in what follows we simplify the notation and drop the subscript $i$ that denotes the source. To make the foregoing model operational, we also need to be specific on the formulation of the trade resistance factor. We write this factor as

$$
T_{j}=\left(1+\tau_{j}\right)\left(1+S_{j}\right)^{\beta}\left(1+D_{j}\right)^{\gamma},
$$

where $T_{j}$ is the trade resistance factor, in country $j$, toward seed imports from the United States; $\tau_{j}$ is the (ad valorem) trade tax on seed corn levied by country $j ; S_{j}$ is a variable capturing the effects of SPS regulation in country $j$ (which we will represent as the count of 
SPS measures that apply to U.S. corn seed exports to country $\jmath){ }^{2} D_{j}$ is the distance from the United States to country $j$; and $\beta$ and $\gamma$ are coefficients that parameterize the effects of SPS variables and distance into tariff factor equivalent effects. More specifically, to measure the SPS effect we use a frequency measure at the commodity market level, a count of SPS regulations affecting U.S. corn seeds. Our model embeds this measure in a cost factor and posits that the cost factor increases in the SPS count to capture its incidence.

With the foregoing parameterization, the import of U.S. corn seed in country $j$ can be written as

$$
X_{j}=\theta Q_{j} c_{j}^{\sigma} W^{-\sigma}\left[\left(1+\tau_{j}\right)\left(1+S_{j}\right)^{\beta}\left(1+D_{j}\right)^{\gamma}\right]^{-\sigma}
$$

where, again, we have dropped the origin subscript (so that, for example, $W$ represents the U.S. corn seed export price). This equation represents the basis of our estimating model in the empirical application. ${ }^{3}$

\section{Empirical Formulation}

The model is estimated with a sample of $M$ observations of U.S. corn seed exports going to $n$ countries. Our empirical model is the log transformation of equation (7), leading to the following specification:

\footnotetext{
${ }^{2}$ The count variable is, admittedly, a crude indicator. A better proxy would aggregate the SPS measures weighted by their cost incidence. The lack of systematic information on the associated cost of each SPS measure rules out the preferred aggregation.

${ }^{3}$ It is readily shown that a share equation version of (7) would include a multilateral trade resistance term, thereby coming closest in spirit to recent gravity equation investigations as it includes a multilateral trade resistance term (e.g., Disdier, Fontagné, and Mimouni, 2008). A disadvantage of such a formulation is that the model is nonlinear in the parameters, and for that reason we do not pursue it further as a vehicle for estimating the structural parameters of the model.
} 


$$
\ln \left(\frac{X_{j t}}{Q_{j t}}\right)=\alpha_{0}+\sigma \ln \left(\frac{c_{j t}}{\left(1+\tau_{j t}\right) W_{t}}\right)-\alpha_{1} \ln \left(1+S_{j t}\right)-\alpha_{2} \ln \left(1+D_{j t}\right)+u_{j t}
$$

where $t=1,2, \ldots, M$ and $j=1,2, \ldots, n$, the coefficients $\alpha_{i}$ are related to the structural parameters as $\alpha_{0}=\ln (\theta), \alpha_{1}=\beta \sigma$, and $\alpha_{2}=\gamma \sigma$, and $u_{i j}$ is an error term that is assumed to be independently and identically distributed, so that observations over all destinations can be pooled.

\subsection{Heteroskedasticity and the "zeros" problem}

Two econometric issues that have been recognized to affect gravity-type of models estimations are those of heteroskedasticity and zero values for the left-hand-side (LHS) variable. Heteroskedasticity in the error term is suspected when the magnitude of the residuals appear proportional to the regression function, the latter being a common property of empirical models in this area. In equation (8), on the other hand, following a common practice in applied econometrics, we allow for some proportionality between errors and trade values by, implicitly, postulating a multiplicative error structure for the model in (7). The error term itself, of course, is assumed to have a constant variance. An alternatively approach, advocated by Silva and Tenreyro (2006) and gaining some popularity, relies on the so-called pseudo Poisson maximum likelihood (PPML) estimation method. This approach estimates the model in levels as in equation (7), with a multiplicative error term and the additional assumption that the conditional variance is proportional to the conditional mean. The claim is that PPML is robust to heteroskedastic errors.

A distinct problem is that of the LHS variable taking on zero values for a sizeable portion of our data set (about 30 percent of the observations). This "zeros problem" presents an immediate challenge for the LHS transformation used in the log-linear model of equation (8). Martin and Pham (2008) and Burger, van Oort and Linders (2009) provide a 
taxonomy and a brief review of the relevant literature and discuss a number of estimation strategies that have been used in this setting. Two common ways of dealing with this problem, in the context of the log-linear model in (8), are: (i) replace zero trade values by a small (arbitrary) number, so as to make the log transformation admissible; or (ii) drop all observation with zero values (i.e., estimated the structural parameters with a truncated sample). The PPML estimation of (the stochastic version of) model (7), on the other hand, can readily admit zero observations for the LHS variable, and that is another reason why it is being advocated as a reasonable model estimation strategy.

All these methods are somewhat unsatisfactory in our context because zero values for the dependent variables here represent true absence of trade, rather than missing observations, and as such are themselves very much in need of explanation. Such a need is ignored by approaches that rely on the truncated sample of positive trade flows only, for example. Similarly, using the full data sample with the log-linear model in (8) (and the arbitrary replacement of zeros by a small number) or the PPML estimation of the model in levels (the stochastic version of (7)), does not address this issue either because, essentially, it treat all zeros equally. But in fact, some zeros might reflect cases that are just at or near the margin where countries are ready to trade. Clearly, such zeros would have a high probability to turn into actual trade and could be modeled as arising from the same process generating the observations with the positive trade volume. In contrast, other zero observations might be associated with high trade costs and thus possess a low probability to turn into positive trade. Perhaps not surprisingly, therefore, a large number of zero observations in the data 
can be problematic with the PPML approach which can suffer from biased estimates as shown by Martin and Pham (2008) and Burger, van Oort, and Linders (2009). ${ }^{4}$

A natural way to handle zero observations in our setting is the sample-selection framework originated with Heckman (1979). As discussed later, this is our preferred approach, because it allows us to identify the impact of changes in exogenous variables on both the likelihood of trade (which we interpret as the "extensive margin") and the existing volume of trade (which we interpret as the "intensive margin"). We apply this estimation procedure to the log-linear model of equation (8). Let $y_{t}$ denote the vector of the LHS variables at time $t$ corresponding to the trade equation (8), and let $z_{t}$ be the corresponding trade indicator variable that takes on value one if positive trade is observed, and value zero if no trade is observed. These observable variables are related to two latent variables that satisfy the following linear processes:

$$
\left[\begin{array}{c}
y_{t}^{0} \\
z_{t}^{0}
\end{array}\right]=\left[\begin{array}{c}
H_{t} \pi \\
L_{t} \psi
\end{array}\right]+\left[\begin{array}{l}
u_{t} \\
v_{t}
\end{array}\right],
$$

where $H_{t}$ and $L_{t}$ are vectors of conditioning variables, $\pi$ and $\psi$ are vectors on unknown parameters, and the error terms have bivariate normal distribution. Specifically,

$$
\left[\begin{array}{l}
u_{t} \\
v_{t}
\end{array}\right] \sim N I D\left(\left[\begin{array}{l}
0 \\
0
\end{array}\right],\left[\begin{array}{cc}
\omega^{2} & \rho \omega \\
\rho \omega & 1
\end{array}\right]\right) .
$$

Finally, the observables of the model are related to these latent variables as follows: $y_{t}=y_{t}^{0}$

if $z_{t}^{0}>0$ and $y_{t}=0$ otherwise; and $z_{t}=1$ if $z_{t}^{0}>0, z_{t}=0$ otherwise. Heckman's (1979) procedure to get consistent estimates in this setting relies on a two-step approach, but given the normality assumption a consistent maximum likelihood estimator is readily possible

\footnotetext{
${ }^{4}$ Zero-inflated Poisson regression could be used but it would leave the sample selection issue unaddressed.
} 
(Davidson and MacKinnon, 2004).

\section{Data Description}

A summary of the data is presented in table 1. The dataset is available from the authors. The U.S. seed corn export data are based on Foreign Agricultural Trade of the United States (FATUS) from the USDA, which reports both value and volume. Under FATUS, volume is derived from value divided by the unit value of the largest seed category. We found some irregularities in the volume data reported in FATUS. Hence, we transformed the seed export value (US\$) into quantities (metric tons) using the U.S. seed corn price in respective years as the average export unit value. This step provides quantity data that are consistent with the value data and that are quality adjusted, as the export volume is expressed in the same volume unit for every country. The U.S. seed corn quantities and prices are from the Economic Research Service (ERS), USDA. Annual seed corn production in the United States is calculated by adding total exports of U.S. seeds to the estimated total domestic (U.S.) use of seeds. ${ }^{5}$ Annual U.S. domestic use of seed is assumed to be equal to corn planted acres times the seed rate as assumed by USDA. Corn planted area for all purposes is taken from the National Agricultural Statistics Service (NASS), Agricultural Statistics Board, USDA. Average seeding rate per acre for corn is based on data from Cropping Practices surveys and the Agricultural Resource Management Survey (ARMS), ERS, USDA. The U.S. corn seed use data are by calendar year.

The seed export data are based on the calendar year. We concentrate on 1989 to 2004 because of the limited export data availability in FATUS. Our final country sample

\footnotetext{
${ }^{5}$ When estimating trade share by country, we compute shares based on total seed use for countries included in the sample, and hence shares do add up to one.
} 
consists of 48 countries based on the following criteria. This sample was selected based on an average minimum corn production of 1 million metric tons ( $\mathrm{mmt}$ ) per year, including seed corn and forage, during the time period of the study. Although its corn production is smaller than $1 \mathrm{mmt}$, Australia was added to the sample because it has very restrictive corn seed regulations (a formal ban except for non commercial corn seed imports) and hence adds across-country variation in the SPS count variable combined to across-country variation in other covariates since Australia's applied tariff is zero. Total world corn production and each country's corn production are based on the Food and Agriculture Organization of the United Nations FAOSTAT.

The FAOSTAT provides production data on Seed Maize (HS code: 1005) as well as Maize for Forage and Silage (HS code: 1214.90). Growers buy hybrid corn seed to produce silage just as they would to produce corn for other purposes. We found inconsistencies between large seed net imports and small corn outputs reported under HS 1005 in some countries in the FAOSTAT data. Notably, we found that Japan, the United Kingdom, and the Netherlands have sizeable imports of corn seeds but no significant seed maize production in the FAOSTAT data. Most of these countries use corn for silage instead of maize. Given these facts, we account for the corn production for silage as being relevant for the overall demand for seed corn. To aggregate these two types meaningfully, we use 8 bushels of grain maize per one ton of silage to get units in green maize physical equivalent. Corn production data are by calendar year. Our original country sample consisted of 54 countries. We deleted Belarus, Moldova, Kazakhstan, and the Russian federation for which we found irregularities (e.g., wide unexplainable swings) in corn production data that could not be reconciled using other data sources. We also deleted Malawi and Nigeria, for which data were incomplete. 
As noted earlier, in our framework the expected producer price of corn is assumed to approximate the (unobserved) unit cost of corn seed production under the assumption of perfect competition in corn production and constant return to scale (unit cost $=$ marginal cost $=$ expected price). Expected prices are, of course, not observable. Notionally, they embed available information at the time expectations are formed, and empirical models for expected prices range from full rational expectation formulations to naïve expectation models. The simple model we use postulates an information set that includes the previousperiod U.S. price (i.e., the most recent price pertaining to the most important market) and a time trend (to capture secular movements in the price of interest). Specifically, we approximate the expected price in any one country as the fitted values of a regression of observed corn prices of that country on the one-period-lagged U.S. corn price and a linear time trend. The current producer price is by calendar year and based on the FAOSTAT.

Tariffs applied to U.S.-sourced corn seeds are based on World Bank's World Integrated Trade Solution (WITS) database (see Table 7 in the Data Appendix). Tariff data are currently limited to 1996-2004 in WITS. Hence, we found some pre-1996 data from the Trade Analysis and Information System (TRAINS) database and Agricultural Market Access Database (AMAD). We use whatever data are available for 1989-1995 in TRAINS and AMAD and backtrack to 1989 assuming the same value for missing information. Tariff data are by calendar year and, although they are expressed in ad valorem form, include all tariffs. WITS and TRAINS are consistent for overlapping years since WITS originate from TRAINS raw data. There were very few overlapping data for tariffs across TRAINS and AMAD sources; hence, no inconsistencies were found between these two sources. Tariffs in most countries exhibit flat or decreasing ad valorem tariffs with the exception of Korea, Hungary, and Poland. In Korea and Hungary, there is a strong increase tariffs in 1996, 
which then decrease in subsequent years. In Poland, the applied tariff increases first in 1996 and then again in 2001.

Direct air distance between the U.S. and the major commercial city of each country is based on Hengeveld's World Distance Tables, which are widely used in gravity equations and available from the Inter-University Consortium for Political and Social Research (ICPSR) database. For each country, one airport has been selected as the major air terminal from the International Air Transport Association Guide on the basis of importance in international passenger and good traffic. For most countries, the name of the airport is identical to the name of the nearest large city in order to use the known geographical latitudes and longitudes of these cities for calculating air distances.

The number of SPS regulations imposed by the importing country is based on data from the Export Certification Project Demonstration (EXCERPT) database maintained at Purdue University on behalf of USDA APHIS. The SPS regulations for each country are updated in 2006 by the EXCERPT. However, older regulations starting from 1996 are reported in the EXCERPT archives. We look at phytosanitary certificates, import permit, and field inspection as well as some other demanding regulatory requirements, including seed testing, post-entry testing, and quarantine. Virtually all countries require a phytosanitary certificate, except Canada. Australia and China have a seed import ban, although China has imported a small amount of seeds in recent years. Some seed lines have to be imported by China to initiate local production. Hence, the Chinese trade ban has not been as tight in recent years, although seed imports remain very small relative to the size of the Chinese corn sector. We use a large number (50) for the SPS count (prohibitive SPS compliance cost) for China and Australia to mimic an SPS count equivalent to the prohibitive policies.

Over time, most countries have streamlined their SPS regulations. Argentina and 
Chile have a low SPS count. The most radical simplifications have occurred in some Eastern European countries, which are now members of the European Union (EU). Notably, in the last 10 years, Hungary started with an SPS count of 68, streamlined it to 30 in 2003, and eventually adopted EU regulations (SPS count of 3) with EU accession in 2004. South Africa, India, and Indonesia also simplified their regulations by removing all SPS requirements. Egypt, Zimbabwe, and, surprisingly, Brazil have very high SPS count (18 requirements). The Brazilian case is puzzling, as the country is a large corn producer that would benefit from accessing better seeds.

\section{Econometric Results}

As noted earlier, the sample-selection framework of equations (9)-(10) represents our favorite estimation strategy although, for comparison, we will also report the results of two single-equation estimation procedures: OLS on the log-linear equation in (8) (where zeros on the LHS are replaced by 0.1); and, the PPML estimation of the stochastic version of the model in (7). The results of these two estimation procedures are reported in Table 2. OLS on the log-linear model and the PPML model produce similar results as far as the sign and significance of the estimated effects, but the estimated magnitude of these effects is quite different. In particular, the PPML approach suggests a larger response to the SPS variable, and a lower response to distance. Another feature of these results that is readily apparent is the difference between the estimates based on the full sample and those based on the truncated sample (positive trade only). This is so even for the PPML approach, which typically is presumed to be more robust to truncation. Hence, it appears that selection bias might be a relevant issue, further motivating the Heckman sample-selection approach.

Table 3 reports results for sample-selection specification in (9)-(10) estimated by 
maximum likelihood (ML), which produces asymptotically efficient estimators. Notice that both the selection and the trade equations depend on the trade cost components (tariff, distance, and SPS). In addition, a time trend as appears in the selection model but not in the trade equation. Such a variable is meant to capture other secular effects on the evolution of trade patterns that are not explained by our limited set of exogenous variables and, in principle, could be advocated for either equation in (9). But the exclusionary restriction that we have adopted is meant to aid identification (Davidson and MacKinnon, 2004). ${ }^{6}$ The selection equation has all parameters significant with the expected sign. The negative signs on the estimated parameters of the trade cost components in the selection model indicate that the likelihood to trade diminishes as the trade cost factors increase. Also, the positive sign on the estimated parameter of the time trend in the selection model indicates that the likelihood to trade has increased over time, consistent with trade integration.

The implied structural parameter estimates are reported in the lower part of Table 3. These structural parameter estimates are significantly different from zero and similar in magnitude to the results reported in Table 2 for the estimation of (8) with the truncated sample. The estimated correlation coefficient $\hat{\rho}$ is negative and statistically significant, indicating a sample selection bias in the data. A comparison of OLS parameter estimates for the log-linear model with the full sample in Table 2 with the ML estimates in Table 3 indicates the selectivity bias that affects the OLS method with full sample. In particular, consider the change in the estimates for distance and SPS from OLS to the ML estimates.

\footnotetext{
${ }^{6}$ Strictly speaking, given the normality assumption, the nonlinearity of the inverse Mills ratio suffices for identification even when the elements of $H_{t}$ and $L_{t}$ are the same. But such an identification strategy is often criticized, and the exclusion of one variable (time trend in our case) is common for identification purposes. In response to a referee's inquiry, we looked at the impact of replacing the time trend with a set of time dummy variables in the selection equation, and that had virtually no effect on the estimated structural parameters.
} 
The coefficient for distance decreases from 0.4157 in OLS to 0.2312 in ML. The coefficient for tariffs decreases from 2.1365 in OLS to 1.4885 in ML. On the other hand, the coefficient for SPS increases from 0.3421 in OLS to 0.4769 in ML. In summary, the impact of distance and tariffs is overestimated and the impact of SPS is underestimated when failing to correct for the selectivity bias in the data.

Although the sample selection approach is popular in empirical analysis, marginal effects are often misinterpreted when a regressor enters into both selection and trade equations. In this case, when $\hat{\rho} \neq 0$, it is incorrect to interpret the estimated parameters of the trade equation shown in Table 3 as the marginal effect. Even if one were interested only in the conditional impact of a regressor (that is, conditional on trade taking place), in addition to the direct impact as per the estimated coefficients one still needs to account for an indirect effect. This is apparent when one recalls that, for observations for which trade takes place, the conditional mean of the trade equation from (9) satisfies (see, e.g., Davidson and MacKinnon, 2004):

$$
E\left[y_{t} \mid y_{t}>0\right]=H_{t} \pi+\rho \omega \frac{\phi\left(L_{t} \psi\right)}{\Phi\left(L_{t} \psi\right)}
$$

where $\phi(\cdot)$ and $\Phi(\cdot)$ denote the density and distribution functions of the standardized

normal, respectively, and $\phi\left(L_{t} \psi\right) / \Phi\left(L_{t} \psi\right) \equiv \lambda_{t}$ is known as the inverse Mills ratio. From (11) it follows that the marginal effect, on the conditional mean, of a regressor $R_{k}$ that appears both in $H_{t}$ and $L_{t}$ is:

$$
\frac{\partial E\left[y_{t} \mid y_{t}>0\right]}{\partial R_{k t}}=\pi_{k}-\psi_{k} \rho \omega\left(\lambda_{t}^{2}+\lambda_{t} L_{t} \psi\right)
$$

Furthermore, when a regressor affects both the intensity of trade and the probability that 
trade takes place, the total unconditional impact is arguably the effect of interest. Following Hoffmann and Kassouf (2005) such an unconditional effect can be written as

$$
\frac{\partial E\left[y_{t}\right]}{\partial R_{k t}}=\frac{\partial E\left[y_{t} \mid y_{t}>0\right]}{\partial R_{k t}}+\frac{\partial \ln \Phi\left(L_{t} \psi\right)}{\partial R_{k t}}
$$

where $\Phi\left(L_{t} \psi\right)=1-\Phi\left(-L_{t} \psi\right)$ is the probability that trade takes place. Hence, to find the unconditional effect of a regressor that affects both the intensity of trade and the probability that trade takes place, the conditional effect in (12) needs to be augmented by $\partial \ln \Phi / \partial R_{k t}=\psi_{k} \lambda_{t}$

The conditional and unconditional marginal effects, evaluated at the sample mean of the observations used to fit the model, are reported in columns 2 and 3 of Table 4 . As noted earlier, we relate these two marginal effects to the intensive and extensive margins to trade. Specifically, the conditional marginal effects represent the elasticities of trade given that trade takes place (intensive margin). The unconditional marginal effects represent the elasticities of trade for all countries, trading and not trading (both intensive and extensive margins). ${ }^{7}$ The estimated unconditional marginal effects for the trade cost components are larger in absolute value than the conditional effects, because the former takes into account both extensive and intensive margins, whereas the latter only measures the intensive margin.

The tariff factor has the largest marginal effect, followed by distance and SPS factors. The striking result is the importance of the distance factor on both trade margins. The

\footnotetext{
${ }^{7}$ As noted by a reviewer, our implicit definition of the extensive margin is somewhat restrictive. More generally, new trade (the extensive margin) can arise because of the emergence of new destinations (Felbermayr and Kohler, 2006), new exported varieties (Hummels and Klenow, 2005), or the participation of new firms on export markets (Helpman, Melitz and Rubinstein, 2008). Because our model considers the same product (no new varieties), and our industry-wide modeling does not identify firm-level activity, we can narrowly interpret the change in the probability to trade as the change in the extensive margin, whereas the change in existing trade is the change in the intensive margin.
} 
estimated parameters in the first column of Table 3 provide a poor gauge of the total marginal effect of the respective explanatory variables on trade.

Distance has the strongest effect on the extensive margin (likelihood to trade) as measured by the difference between the unconditional and conditional marginal effects. This suggests that transportation cost (as proxied by distance) is the major trade cost inhibitor of the emergence of new trade followed by tariffs and SPS measures and policies decreasing these costs associated with distance would presumably have a large impact. However, at the intensive margin, tariffs matter the most followed by distance and SPS measures.

In summary, the results show that trade costs do matter considerably in corn seed trade. Tariff factors have the largest effect, followed by the cost factor reflecting geographical distance, and last, the factor for SPS regulations, provided that sample selection bias is properly addressed. Gauging the effects of trade costs based on the estimation of the intensive margin alone would be quite misleading. When properly computed using marginal effects derived from the sample selection model, the magnitude and ranking of the impacts of these trade costs on seed trade differ from the estimated regression coefficients on which they are based. The marginal effects are much larger in absolute value than the associated coefficients and reveal the relative importance of cost associated with distance.

We also note that our responses to distance are within the range of estimates reviewed by Disdier and Head (2008). Average tariffs on the U.S. seed trade have been moderate (10 percent in our sample) over the last two decades. Yet, the high response of corn seed exports to tariffs suggests that tariffs remain an important barrier that could be further reduced. Removing the remaining tariffs evaluated (in 2004) would increase existing (2004) seed trade by roughly $12 \%$, specifically $11 \%$ through intensified trade and $1 \%$ through new trade. These estimates are obtained by applying the conditional marginal effect 
to the removal of positive ad valorem tariffs in countries with positive trade and by computing the extensive margin effect of removing the positive tariff in countries with no trade and applying it to the average observed trade level for 2004. The small effect on new trade occurs because many countries with positive tariffs have positive trade already and several countries with no trade have zero tariffs.

SPS regulations also pose a significant barrier to U.S. seed exports but unlike for tariffs, a complete unilateral removal may not be beneficial as externalities could occur in absence of SPS regulations. Nevertheless, in most case, a few SPS measures would suffice, such as a SPS certificate, eventual field inspection, or occasional treatments, focusing on the few relevant pests for each importing country. These few measures would be sufficient to eradicate most if not all vectors of externalities for corn seeds (Mcgee, 1998). For the sake of estimating a trade effect from rationalizing SPS measures, we conjecture that five SPS measures would be sufficient to maintain the SPS integrity of the seeds to all destinations and compute the associated trade effects from removing SPS policies in excess of this reference count in 2004. This approach is somewhat arbitrary but provides an order of magnitude to a potential rationalization of SPS policies in export markets. As for tariffs, we apply the implied proportional reduction of SPS measures to the intensive margin for countries with positive trade and then apply the proportional reduction in SPS count to the extensive margin for countries with no trade, weighted by the average trade level prevailing in 2004. The total trade expansion effect of rationalizing SPS regulations is nearly $8.8 \%$ of which $0.4 \%$ comes from the extensive margin (i.e., new trade). ${ }^{8}$

In sum, although the extensive margin is a critical component of the unconditional

\footnotetext{
${ }^{8}$ If only three SPS measures were necessary to maintain the SPS integrity of the seeds, then the total expansion of trade would be $11.4 \%$, of which $0.7 \%$ through the extensive margin.
} 
(total) trade margin, trade expansion from tariff liberalization and SPS policy rationalization would come principally through intensification of existing trade rather than from new export destinations.

\section{Concluding Remarks}

The U.S. seed market is the largest in the world and is expanding. Seed trade has been an important part of this expansion. Despite these facts, seed trade and its determinants remain a somewhat neglected topic in agricultural trade research. We fill this gap with an analysis of trade costs associated with U.S. corn seed trade. We develop a parsimonious seed export demand model with a sound conceptual foundation based on derived demand in production, accounting for major trade costs including transportation, tariff factors, and the cost of SPS measures affecting seed trade flows. We use a count of SPS regulations affecting U.S. corn seeds embedded in a cost factor and posit that the cost factor increases in the SPS count.

We estimate the export demand equation based on a log-linear specification of seed export levels and using Heckman's sample selection model. The major empirical findings of the study are that all the trade costs have a statistically significant and negative impact on U.S. corn seed exports. The sample selection procedure addresses the large number of zerotrade observations in the data and is motivated by evidence of sample selection bias with alternative methods. The sample selection procedure also allows computing extensive and intensive margins of trade when trade costs components are altered. Based on marginal effects computed from the sample selection model, the decreasing order of importance for trade costs is first tariffs, followed by distance, and then SPS regulations.

This study contributes to the existing literature in several ways. The research question addressed here, namely, the determinants of seed export demand, appears to have 
been ignored to date in the economic literature. Further, we derive a gravity-like approach to export demand based on derived demand in production unlike in other applications of the gravity model to agricultural trade based on final demand. Lastly, the dataset collected for the investigation is also novel in its SPS component and the development of the SPS count variable.

Our analysis has relevant policy and political economy implications. Trade policy barriers matter much in trade costs. Tariffs on agricultural goods remain important, although they have somewhat decreased with the Uruguay round of the World Trade Organization and with regional trade agreements. Tariffs on seed trade have been moderate (an average of 10 percent in our sample). Nevertheless, the high response of corn seed exports to tariffs suggests that tariffs remain an important barrier that could be further reduced. We estimate that the removal of remaining tariffs would induce a $12 \%$ increase in U.S. corn seed trade.

The importance of trade costs induced by SPS regulations raises the issue of sorting which of these regulations are legitimate, that is, science based, and which are not and could be eliminated or challenged using the W'TO dispute settlement body. We consider a rationalization of "excess" SPS measures in countries ridden by many SPS policies. We find that such rationalization would increase trade by nearly $9 \%$, mostly through intensification of trade. In the data presentation we also noted the important policy development in the enlarged European Union. The streamlining of SPS measures among EU-27 members has facilitated much trade expansion in the last decade.

When looking at these two policies together, the political economy of SPS measures in seed markets does not seem to fit the traditional argument of SPS and tariffs being policy substitutes in rent-seeking activities. Both have been significantly decreased with a few exceptions for applied tariffs. SPS measures have not risen and substituted for falling tariffs 
through our 1989-2004 time span. The correlation between tariff and SPS is statistically weak and does not suggest any strategic interaction from rent-seeking pressures.

Finally, distance is irreducible of course, but cost associated with distance and transportation could be reduced, and could lead to new trade and intensification of existing trade. 


\section{References}

Anderson, K., C. McRae, and D. Wilson, eds. (2001). The Economics of Quarantine and the SPS Agreement. Centre for International Economic Studies and the Department of Agriculture, Fisheries and Forestry - Australia/Biosecurity Australia, Adelaide.

Beghin, J. (2008a). "Nontariff Barriers," in The New Palgrave Dictionary of Economics, $2^{\text {nd }}$ Edition, S. Darlauf and L. Blume, eds., Palgrave Macmillan LTD: 126-129.

Beghin, J., and J.C. Bureau. (2001). "Quantitative Policy Analysis of Sanitary, Phytosanitary and Technical barriers to Trade," Economie Internationale 87: 107-130.

Burger, M., F. van Oort, and G-J. Linders. (2009). "On the Specification of the Gravity Model of Trade: Zeros, Excess Zeros and Zero-inflated Estimation.” Spatial Economic Analysis 4(2): 167-190

Cipollina, M., and L. Salvatici. (2008). “Measuring Protection: Mission Impossible?” Journal of Economic Surveys 22(3): 577-616.

Calvin, L., B. Krissoff, and W.E. Foster. (2008). "Measuring the Costs and Trade Effects of Phytosanitary Protocols: A U.S.-Japanese Example." Review of Agricultural Economics 30 (1): 120-135.

Davidson, R., and J.G. MacKinnon (2004). Econometric Theory and Methods. New York: Oxford University Press.

Deardorff, Alan V., and Robert M. Stern. (1998). Measurement of Nontariff Barriers: Studies in International Economics. Ann Arbor MI: University of Michigan Press.

Disdier, A.C., L. Fontagné, and M. Mimouni. (2008). “The Impact of Regulations on Agricultural Trade: Evidence from SPS and TBT Agreements," American Journal of Agricultural of Economics 90 (2): 336-350.

Disdier, A.C., and K. Head. (2008). “The Puzzling Persistence of the Distance Effect on 
Bilateral Trade," Review of Economics and Statistics 90 (1): 37-48.

Felbermayr, G.J., and W. Kohler. (2006). "Exploring the Intensive and Extensive Margins of World Trade." Review of World Economics 142: 642-674.

Fernandez-Cornejo, J. (2004). "The Seed Industry in U.S. Agriculture. An Exploration of Data and Information on Crop Seed Markets, Regulation, Industry Structure, and Research and Development," USDA ERS Agricultural Information Bulletin No. 786, Washington, DC.

Fernandez-Cornejo, J., and M. Caswell. (2006). "The First Decade of Genetically Engineered Crops in the US," Economic Information Bulletin 11, USDA.

Ghazalian, P, L. Tamini, B. Larue, and J.P. Gervais. (2007). “A Gravity Approach to Evaluate the Significance of Trade Liberalization in Vertically-Related Goods in the Presence of Non-tariff Barriers.” MPRA Paper No. 2744, Munich Personal RePEc Archive.

Heckman, J.J. (1979) "Sample Selection Bias as a Specification Error", Econometrica 47: 153161.

Helpman, E., M. Melitz, and Y. Rubinstein (2008) "Estimating Trade Flows: Trading Partners and Trading Volumes," The Quarterly Journal of Economics 123 (2): 441-487.

Henson, S., and J.S. Wilson. (2005). The WTO and Technical Barriers to Trade. Aldershot, UK: Edward Elgar Publishing.

Hoffmann, R., and A.L. Kassouf. (2005). "Deriving Conditional and Unconditional Marginal Effects in Log Earnings Equations Estimated by Heckman's Procedure.” Applied Economics 37 (11): 1303-1311.

Hummels, D., and P.J. Klenow. (2005). “The Variety and Quality of Nation's Exports.” American Economic Review 95: 704-723. 
Martin, W., and C. Pham. (2008) "Estimating the Gravity Model when Zero Trade Flows Are Frequent," World Bank Working Paper, January.

Maskus, K.E., and J.S. Wilson. (2001). Quantifying the Impacts of Technical Barriers to Trade, Can It Be Done? Ann Arbor, MI: The University of Michigan Press.

McGee, D.C. (1998). “Initiatives to Improve the International Seed Health System.” Seed Technology 20: 18-22.

Moenius, J. (2006). "The Good, the Bad, and the Ambiguous: Standards and Trade in Agricultural Products," Paper prepared for the IATRC (International Agricultural Trade Research Consortium) Summer Symposium, Bonn, Germany, May 28-30.

Peterson, E.B., and D. Orden. (2008). “Avocado Pests and Avocado Trade” American Journal of Agricultural Economics 90 (2): 321 - 335.

Rohrbach, D.D., I.J. Minde, and J. Howard. (2003). "Looking Beyond National Boundaries: Regional Harmonization of Seed Policies, Law and Regulations," Food Policy 28: 317 333.

Silva, J.M.C.S., and S. Tenreyro. (2006) “The Log of Gravity”, Review of Economics and Statistics 88(4): 641-658.

Yue, C., and J. Beghin. (2009). "The Tariff Equivalent and Forgone Trade Effects of Prohibitive Technical Barriers to Trade," American Journal of Agricultural Economics 91(4): 930-941.

Yue, C., J.C. Beghin, and H.H. Jensen. (2006). “Tariff Equivalent of Technical Barriers to Trade with Imperfect Substitution and Trade Costs," American Journal of Agricultural Economics 88 (4): 947-960. 
Table 1. Data Summary

\begin{tabular}{|c|c|c|c|c|c|c|c|}
\hline variable & Mean & Std Dev & Minimum & Maximum & \multicolumn{3}{|c|}{ Units } \\
\hline SPS count $S$ & 9.602 & 14.366 & 0 & 68 & \multicolumn{2}{|c|}{ count } & \\
\hline Distance $D$ & 8542.071 & 3268.792 & 0 & 15801 & \multicolumn{2}{|c|}{ miles } & \\
\hline $\operatorname{tariff} \tau$ & 9.915 & 39.38 & 0 & 357.6 & \multicolumn{2}{|c|}{ Ad val. $(\%)$} & \\
\hline US Seed use $X$ & 14218.292 & 87492.541 & 0 & 653424.5 & \multicolumn{2}{|c|}{ Metric tons } & \\
\hline expected unit cost $c$ & 175.145 & 158.317 & 23.795 & 1194.178 & \multicolumn{2}{|c|}{$\mathrm{US} \$ / \mathrm{mt}$} & \\
\hline US seed price fob $W$ & 3644.237 & 481.886 & 3082.062 & 4629.706 & \multicolumn{2}{|c|}{$\mathrm{US} \$ / \mathrm{mt}$} & \\
\hline Corn production $Q$ & 13572.09 & 39632.325 & 57 & 319692.188 & \multicolumn{2}{|c|}{$1000 \mathrm{mt}$} & \\
\hline \multicolumn{8}{|c|}{ Correlation among Variables } \\
\hline & $S$ & $D$ & $\tau$ & $X$ & $c$ & $W$ & $Q$ \\
\hline SPS count $S$ & 1 & & & & & & \\
\hline Distance $D$ & -0.001 & 1 & & & & & \\
\hline tariff $\tau$ & 0.023 & 0.240 & 1 & & & & \\
\hline US Seed use $X$ & -0.102 & -0.404 & -0.040 & 1 & & & \\
\hline expected unit cost $c$ & -0.067 & 0.130 & 0.193 & -0.079 & 1 & & \\
\hline US seed price fob $W$ & -0.041 & 0.004 & 0.086 & 0.008 & -0.061 & 1 & \\
\hline Corn production $Q$ & 0.081 & -0.349 & -0.010 & 0.898 & -0.128 & 0.031 & 1 \\
\hline
\end{tabular}


Table 2. U.S. Corn Seed Exports: OLS on log-linear model, and PPML model

\begin{tabular}{|c|c|c|c|c|}
\hline \multirow[t]{3}{*}{ Variable } & \multicolumn{4}{|c|}{ Estimated structural parameters with: } \\
\hline & \multicolumn{2}{|c|}{ Full sample } & \multicolumn{2}{|c|}{ Truncated sample } \\
\hline & Log-linear & PPML & Log-linear & PPML \\
\hline Intercept $\left(\alpha_{0}\right)$ & $\begin{array}{l}11.1817^{*} \\
(1.3173)\end{array}$ & $\begin{array}{l}4.5941^{*} \\
(.4548)\end{array}$ & $\begin{array}{l}\text { 7.284* } \\
(0.7910)\end{array}$ & $\begin{array}{l}3.7133^{*} \\
(0.4466)\end{array}$ \\
\hline Distance $(\gamma)$ & $\begin{array}{l}0.4157^{*} \\
(0.0666)\end{array}$ & $\begin{array}{l}0.0784^{*} \\
(0.0243)\end{array}$ & $\begin{array}{l}0.2552^{*} \\
(0.0433)\end{array}$ & $\begin{array}{l}0.0287 \\
(0.0318)\end{array}$ \\
\hline $\operatorname{SPS}(\beta)$ & $\begin{array}{l}0.3421^{*} \\
(0.0914)\end{array}$ & $\begin{array}{l}1.3293^{*} \\
(0.1489)\end{array}$ & $\begin{array}{l}0.4732^{*} \\
(0.0809)\end{array}$ & $\begin{array}{l}1.5898^{*} \\
(0.2109)\end{array}$ \\
\hline $\begin{array}{l}\text { Elasticity of } \\
\text { substitution }(\sigma)\end{array}$ & $\begin{array}{l}2.1365^{*} \\
(0.2672)\end{array}$ & $\begin{array}{l}.9775^{*} \\
(0.1116)\end{array}$ & $\begin{array}{c}1.5794^{*} \\
(0.1642)\end{array}$ & $\begin{array}{l}0.7730^{*} \\
(0.1075)\end{array}$ \\
\hline $\begin{array}{l}\mathrm{R}^{2} \text { (Pseudo } \mathrm{R}^{2} \text { for } \\
\text { PPML) }\end{array}$ & 0.2016 & 0.1877 & 0.2976 & 0.1732 \\
\hline Observations & 709 & 709 & 490 & 490 \\
\hline
\end{tabular}

Note: In the log-linear model with full sample, $X_{j t}$ replaced by $X_{j t}+0.1$ when $X_{j t}=0$. Standard errors are in parentheses; ${ }^{*}$ denotes significant at the $1 \%$ level. 
Table 3. Maximum likelihood (ML) estimation of sample selection model Log linear gravity equation specification

\begin{tabular}{|c|c|c|c|c|}
\hline \multirow[b]{2}{*}{ Variable } & \multicolumn{2}{|c|}{ Selection equation } & \multicolumn{2}{|c|}{ Log of trade equation } \\
\hline & $\begin{array}{l}\text { Parameter } \\
\text { estimate }\end{array}$ & $\begin{array}{l}\text { Standard } \\
\text { error }\end{array}$ & $\begin{array}{l}\text { Parameter } \\
\text { estimate }\end{array}$ & $\begin{array}{l}\text { Standard } \\
\text { error }\end{array}$ \\
\hline Intercept & $16.4842^{*}$ & 1.7996 & $6.7485^{*}$ & 0.8297 \\
\hline Time & $0.0596^{*}$ & 0.0134 & & \\
\hline $\ln \left(1+D_{j}\right)$ & $-1.6129^{*}$ & 0.1915 & $-0.3442^{*}$ & 0.0657 \\
\hline $\ln \left(1+S_{j}\right)$ & $-0.1702^{*}$ & 0.0559 & $-0.7098^{*}$ & 0.1025 \\
\hline $\ln \left(c_{j} /\left(\left(1+\tau_{j}\right) W\right)\right)$ & $0.4747^{*}$ & 0.1236 & $1.4885^{*}$ & 0.1703 \\
\hline \multicolumn{5}{|c|}{ Recovered parameters } \\
\hline Distance $(\gamma)$ & & & 0.2312 & 0.0465 \\
\hline $\operatorname{SPS}(\beta)$ & & & 0.4769 & 0.0871 \\
\hline $\begin{array}{l}\text { Elasticity of } \\
\text { substitution }(\sigma)\end{array}$ & & & 1.4885 & 0.1703 \\
\hline$\hat{\rho}$ & & & $-0.3645^{*}$ & \\
\hline$\hat{\omega}$ & & & 2.1508 & \\
\hline Observations & 709 & & 494 & \\
\hline
\end{tabular}

Note: Maximized log-likelihood value $=-1430.75$, and ${ }^{*}$ denotes significance at the $1 \%$ level. 
Table 4: Conditional and unconditional marginal effects of trade costs

\begin{tabular}{llll}
\hline Variable & $\begin{array}{l}\text { estimated } \\
\text { coefficient of } \\
\text { trade equation }^{\mathrm{a}}\end{array}$ & $\begin{array}{l}\text { Conditional } \\
\text { marginal } \\
\text { effect }^{\mathrm{b}}\end{array}$ & $\begin{array}{l}\text { Unconditional } \\
\text { marginal } \\
\text { effect }^{\mathrm{b}}\end{array}$ \\
\hline $\ln \left(1+D_{j}\right)$ & -0.3442 & -0.9921 & -1.8091 \\
$\ln \left(1+S_{j}\right)$ & -0.7098 & -0.7782 & -0.8644 \\
$\ln \left(c_{j} /\left(\left(1+\tau_{j}\right) W\right)\right)$ & 1.4885 & 1.6792 & 1.9194
\end{tabular}

\footnotetext{
${ }^{a}$ First column from table 2.

${ }^{\mathrm{b}}$ Because we use log specifications, these effects correspond to elasticities (see derivations in text).
} 
Iowa State University does not discriminate on the basis of race, color, age, religion, national origin, sexual orientation, gender identity, sex, marital status, disability, or status as a U.S. veteran. Inquiries can be directed to the Director of Equal Opportunity and Diversity, 3680 Beardshear Hall, (515) 294-7612. 